$\mathrm{DOE} / \mathrm{CE} / \hat{10938--1}$

DE92 004027

\title{
Collection of VLE Data for \\ Acid Gas - Alkanolamine Systems \\ Using Fourier Transform Infrared Spectroscopy
}

Phase 1 Report

for Period September 29, 1990 - September 30, 1991

Jerry A. Bullin and Richard 2 . Frazier

Texas Engineering Experimental Station Texas A \& M Univesity

College Station, TX 77843-3577

September 1991

Prepared for

THE U. S. DEPARTMENT OF ENERGY AGREEMENT NO. DE-FC02-90CE40938

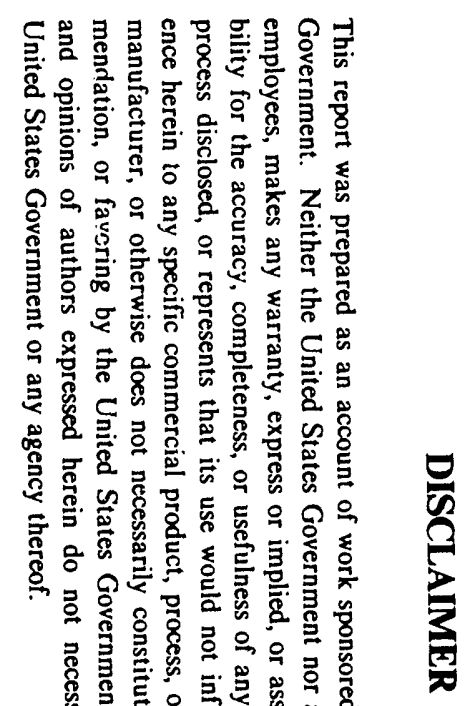

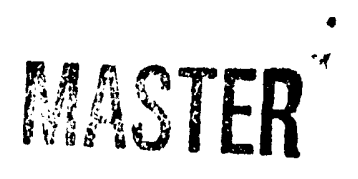


N O T I C E

This report was prepared as an account of work sponsored by the United States Government. Neither the United States nor the Department of Energy, nor any of their employees, nor any of their contractors, subcontractors, or their employees, makes any warranty, express or implied, or assumes any legal liability or responsibility for the accuracy, completeness, or usefulness of any irformation, apparatus, product or process disclosed or represents that its use would not infringe privately-owned rights. 
Table of Contents

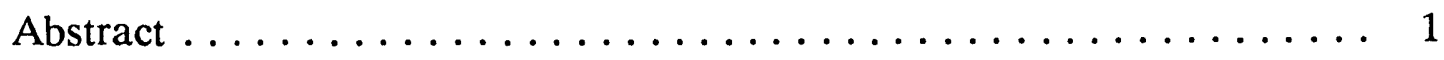

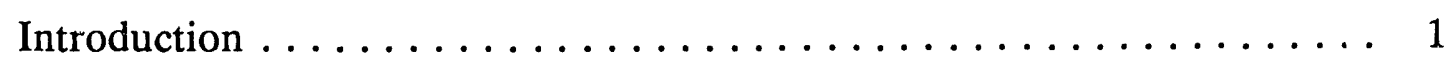

Scope of Investigation $\ldots \ldots \ldots \ldots \ldots \ldots \ldots \ldots \ldots \ldots \ldots \ldots \ldots \ldots$

Significant Results ....................... 4

Compliance with Agreement Requirements $\ldots \ldots \ldots \ldots \ldots \ldots$

Project Econonic Update . . . . . . . . . . . . . . . . . . 11

References ............................ 12

\section{List of Figures}

Figure 1 Alkanolamine Purification Process ............... 13

Figure 2 Hydrogen Sulfide Spectrum at 15 PSIA and $5 \mathrm{~cm}$. Pathlength ................. 14

Figure 3 Hydrogen Sulfide Spectrum at 0.2 PSIA and 86 Meters Pathlength ................ 15 


\begin{abstract}
The industrial standard process for the purification of natural gas is to remove acid gases, mainly hydrogen sulfide and carbon dioxide, by the absorption and reaction of these gases with alkanolamines. Inadequate data for vapor - liquid equilibrium (VLE) hinder the industry from converting operations to more energy efficient amine mixtures and conserving energy. Some energy reductions have been realized in the past decade by applying such amine systems as "hindered" amines, methyldiethanolamine (MDEA), and MDEA based amine mixtures. However, the lack of reliable and accurate fundamental VLE data impedes the commercial application of these more efficient alkanolamine systems. The first project objective is to improve the accuracy of vapor - liquid equilibrium measurements at low hydrogen sulfide concentrations. The second project objective is to measure the VLE for amine mixtures. By improving the accuracy of the VLE measurements on MDEA and mixtures with other amines, energy saving can be quickly and confidently implemented in the many existing absorption units already in use. If about $25 \%$ of the existing 95.3 billion SCFD gas purification capacity is converted to these new amine systems, the energy savings are esti.nated to be about $3 \times 10^{14} \mathrm{BTU} / \mathrm{yr}$.
\end{abstract}

\title{
INTKODUCTION
}

The industrial standard process for the purification of natural gas is to remove acid gases, mainly hydrogen sulfide $\left(\mathrm{H}_{2} \mathrm{~S}\right)$ and carbon dioxide $\left(\mathrm{CO}_{2}\right)$, by the absorption and reaction of these gases with alkanolamines. Monoethanolamine (MEA) and diethanolamine (DEA) are the predominate alkanolamines used by natural gas processors, refiners, ammonia producers, and synthetic gas producers. The gas stream contaminated with acid gases, called a sour gas stream, is fed to an absorber column where $i \hat{\imath}$ is contacted countercurrently with a solution of alkanolamine and water. This process is 
sketched in Figure 1. After the acid gases are absorbed, the reacted alkanolamine, or rich amine, is sent to a regeneration or stripper column. The chemical reaction is reversed and the acid gases are stripped from the solution by adding heat. Since the regenerator is operated at elevated temperature, the lean amine stream is cross-exchanged with the rich amine stream for heat recovery. Excessive pumping energy and reboiler duty are consumed when these gas purification units are operated within equilibrium pinch zones where there is a lack of accurate VLE data for acid gas - alkanolamine mixtures. Inadequate models for VLE, kinetics, and mass transport hinder the industry from converting operations to more energy efficient amine mixtures and conserving energy. In addition to energy waste, the inefficient gas purification operations result in the combustion of additional fossil fuel, primarily natural gas, to produce the energy required for the purification process. Thus the wasted energy also results in the release of additional $\mathrm{CO}_{2}, \mathrm{CO}$, and $\mathrm{NO}_{\mathrm{x}}$ combustion byproducts into the atmosphere.

Some energy reductions have been realized in the past decade by applying such amine systems as "hindered" amines, methyldiethanolamine (MDEA), or MDEA based amine mixtures. ${ }^{[4,5,7]}$ MDEA based amines have demonstrated greater solvent capacity and selective absorption for $\mathrm{H}_{2} \mathrm{~S}$ in many applications now serviced by MEA and DEA. Additional advantages for MDEA amine systems are an improved corrosion performance, a lower heat of reaction, a higher solution concentration, and an improved solution stability. Designs that incorporate these advantages of MDEA based amines can reduce the pumping energy and reboiler duty of amine operations from 25 to $60 \%$. However, tire lack of reliable and accurate fundamental VLE data impedes the commercial application of these more efficient alkanolamine systems. The most critically deficient area for VLE data occurs in the lean amine equilibrium pinch zones in the bottom of the stripper and top of the absorber. The lean pinch zones typically have $\mathrm{H}_{2} \mathrm{~S}$ partial pressures less than 0.1 psia and loadings less than $0.01 \mathrm{~mol} / \mathrm{mol}$ of amine. Other important areas include the high temperature pinch zones within 
the absorber and the rich amine equilibrium pinch zone in the bottom of the absorber. The rich pinch zones can have extremely high acid gas partial pressures but usually less than 200 psia.

Natural gas processors and petroleum refiners are the two major industries using alkanolamine purification. The amount of gas processed by these industries is about 95.3 billion standard cubic feet per day (BSCFD). MDEA based amines have the potential of saving energy in more than 28 BSCFD of this total processed volume. Without new accurate amine VLE data for MDEA based amine mixtures, 25 BSCFD of this processed gas will not realize the full potential energy savings. The energy savings potential for the conversion of 25 BSCFD capacity to these more efficient amines is estimated to be about $3 \times 10^{14}$ BTU/yr. At current gas prices, this amount of energy is equivalent to about $\$ 500$ million a year.

\section{SCOPE OF INVESTIGATION}

The overall project has two major objectives. The first is to improve the accuracy of vapor - liquid equilibrium measurements at low hydrogen sulfide concentrations. The second is to measure the VLE for amine mixtures. The objectives are pursued in three phases each lasting about one year. Phase I will develop and demonstrate the application of quantitative infrared spectroscopy to VLE measurements of acid gas - DEA systems. The infrared technique will improve the accuracy of conventional methods in the low hydrogen sulfide concentration range. The technique also allows a more thorough analysis of the liquid phase reaction products. Phase II will then expand the technique to include MDEA. Phase II equilibrium measurements will include MDEA and a mixture of MDEA - DEA. Once the technique for mixtures of two amines is developed in Phase II, the technique will be used in Phase III for measurements of MEA and MDEA - MEA amine mixtures. 


\section{SIGNIFICANT RESULTS}

The following measurable objectives were cited in the original proposal and expected to be completed by September 1, 1991.

1. A technical paper describing the equilibrium equipment and infrared measurement technique.

2. A set of equilibrium data for DEA which will demonstrate the accuracy of the infrared technique.

3. A report for the Department of Energy summarizing the work completed during Phase I.

Measurable objective \#1 is the product of Task 3 and is expected to be delivered by May 31, 1992. Measurable objective \#2 is expected to be delivered by January 31, 1992. Measurable objective \#3 is this report.

Several intermediate results have been obtained during Phase 1. These results have demonstrated that the project is feasible. Emphasis has been placed on the construction and testing of the three major equipment pieces; a $14 \mathrm{~cm}$. gas transmittance cell, a multipass gas transmittance cell with adjustable pathlengths from 26 to 86 meters, and a liquid circular internal reflectance (CIR) cell. The multipass gas transmittance cell and the $14 \mathrm{~cm}$. gas transmittance cell are custom built devices for taking high temperature and pressure gas measurements. Only the CIR cell is a standard commercial device capable of fitting within the infrared spectrometer. However, the three analytical devices must be positioned so that the infrared beam can be directed to each device. Each device piece is positioned outside the infrared spectrometer on a portable framework. This requires the installation of additional optics to redirect and refocus the infrared beam before reaching the analytical devices. The CIR cell and the $14 \mathrm{~cm}$. gas transmittance cell require eight input mirrors to properly condition the infrared beam and eight more to return the beam to the spectrometer infrared detector. The input and output optics for the multipass cell were limited to three mirrors for each direction. This is because of the difficult task of aligning the optics external to the 
cell with the internal optics inside the multipass cell. The internal optics of the multipass cell include nine mirrors designed to fold up to 86 meters of infrared beam path into a space one meter long. During Phase I, each of the major analytical devices has been assembled and positioned within the experimental apparatus. Subsequent testing of the equipment required several design changes in the gas transmittance cells and in the input optics. Presently, all the analytical devices have been successfully tested and have produced acceptable test spectra.

The multipass gas transmittance cell is the critical device for this research. The cell is also the most difficult to design, construct, and operate. The purpose of the multipass gas transmittance cell is to detect small concentrations of $\mathrm{H}_{2} \mathrm{~S}$ in the gas phase. The objective is to detect concentrations in the part per million range. This is equivalent to a partial pressure of 0.001 psia. The detectability limit of the multipass cell has been tested using $\mathrm{H}_{2} \mathrm{~S}$. The test produced a very good spectrum of reasonable signal - to - noise ratio. At present the lower detectable limit is 0.02 psia. Further optimization in the detector response and measurement technique should allow us to approach the lower detectable limit desired. The hydrogen sulfide spectrum for atmospheric (14.7 psia) $\mathrm{H}_{2} \mathrm{~S}$ is shown in Figure 2. The comparative $\mathrm{H}_{2} \mathrm{~S}$ spectrum obtained at 0.2 psia is shown in Figure 3. Both figures clearly show the distinctive absorbance frequencies for $\mathrm{H}_{2} \mathrm{~S}$.

\section{COMPLIANCE WITH AGREEMENT REQUIREMTNTS}

Phase One was divided into the following tasks, subtasks and milestones. The tasks, subtasks, and milestones were derived from the original proposal and beginning milestone plan. For each task listed, a summary is given describing whether the task is complete, what problems have arisen, and any new schedule corrections.

\section{Task 1: Technique Development}

Compliance/Failure. This task has not been completed as scheduled. 
Several equipment tests have indicated that the technique is feasible. No alterations are foreseen in the planned approach to completing this task. Further details are provided for each subtask.

Problems. Several equipment design problems have been encountered and have resulted in delays of several months. One delay was encountered with the alignment of the mirrors in the multipass cell. The alignment laser internal to the FTIR is not concentric with the infrared beam. Therefore, a separate alignment laser was installed and aligned with the infrared beam. This delay was a.bout one month. The second delay occurred when the multipass cell was tested for infrared power throughput. The infrared detector signal strength was not strong enough to measure the gases inside the multipass cell. This poor signal - to - noise ratio was improved by several design alterations including increasing the diameter of the infrared windows, increasing the source power, and decreasing the number of reflections within the multipass cell. This delay totaled three months. The third delay recently involved the seal integrity and mechanical strength of the infrared windows. The infrared windows of the multipass cell were fracturing when installed and leaking during the pressure tests. The gasket seal material was changed from Teflon ${ }^{\star}$ to neoprene. This appears to have solved the stress problems encountered during the installation of the windows.

Schedule Update. The projected completion date for this task is now Dec. 1, 1991.

\section{Subtask 1a: (Milestone 1)}

Identification of the Unique Spectrum Frequencies for Each of the System Components. The infrared spectra of each system component; water, diethanolamine, hydrogen sulfide, and carbon dioxide; will be recorded at a resolution of $0.5 \mathrm{~cm}^{-1}$ wavenumbers. The observed frequencies will be catalogued as pure component frequencies or impurity component frequencies. Impurity identification will be attempted with a gas chromatographic separation and subsequent infrared analysis. 
Compliance/Failure. This task has not been completed as scheduled. One detailed spectrum of hydrogen sulfide was produced in an equipment test to determinc the limit of detectability. Delays in the construction of the equilibrium apparatus have delayed the performance of this task.

Schedule Update. The performance of this task will be concurrent with the calibrations of subtask 1b. Completion is scheduled for October 15, 1991.

\section{Milestone 2}

Pressure Test of the Equilibrium Equipment. After construction, the equilibrium apparatus must be tested to verify the integrity of the apparatus. The apparatus must be able to confine all the system components under pressure for the time period of an experimental run. The test is a 24 hour 100 psig nitrogen pressure test of the entire apparatus. The test is successful if no pressure loss is detected within the 0.2 psig detectability limit of the test pressure gauge.

Compliance/Failure. This task is partially completed. Only the vapor circulation loop and all the vessels have been successfully tested.

Problems. The dynamic seals of the circulation pumps could not be tightened enough to seal against the shafts. The vapor and liquid pumps were replaced with two pump designs without dynamic seals.

Schedule Update. This task will be completed by September 15, 1991.

\section{Milestone 3: Complete the First Quarterly Report}

Compliance/Failure. This task has been completed.

\section{Subtask 1b: (Milestone 4)}

Calibration of the FTIR Response for Each of the Component Concentrations. The relationship between infrared absorbance and the component concentration must be established for each component. The calibration effort includes identifying whether the relationship between concentration and absorbance is linear or non-linear anc determining the relative 
ratio between component frequencies at several sets of opcrating conditions.

Compliance/Failure. This task is not complete.

Problems. The equilibrium apparatus must first pass the pressure test.

Schedule Update. This task will be completed by October 15, 1991.

Subtask 1c: (Milestone 5)

Demonstration of the Quantitative Response of the System Mixture. A well studied system mixture of $\mathrm{H}_{2} \mathrm{~S}-\mathrm{CO}_{2}$ - DEA will be tested to confirm the additive properties of the individual components. Reaction products also will be identified as possible. The system mixture will be of a compositional range which is accurately measured using gas chromatography. Chromatographic analysis will be used to confirm the accuracy of the infrared technique.

Compliance/Failure. This task is not complete.

Schedule Update. This task will be completed by December 1, 1991.

\section{Milestone 6: Complete the Second Quarterly Report}

Compliance/Failure: This task has been completed.

\section{Subtask 1d}

Determination of Temperature and Pressure Limits for the System Mixtures. The system will be developed within a typical pressure and temperature range for gas sweetening operation. However, it is not presently known if the infrared technique wili work in the extremely high temperature and pressure ranges of some sweetening operations. A series of experiments will determine the operational limits of this new technique. The upper bounds of interest are about $250^{\circ} \mathrm{F}$ and 500 psia.

Compliance/Failure. This task is not complete.

Schedule Update. This task will be completed by December 31, 1991.

\section{Task 2: (Milestone 7)}

Technique Authentication. Determine vapor - liquid equilibrium data for 
a $\mathrm{H}_{2} \mathrm{~S}-\mathrm{CO}_{2}-$ DEA system different from the one used in Subtask 1c. The DEA system will be used to authenticate the infrared technique. The new DEA system will be within a compositional range suitable for gas chromatographic analysis.

Compliance/Failure. This task is not complete.

Schedule Update. This task will be completed by January 31, 1992.

Milestone 8: Complete the Third Quarterly Report

Compliance/Failure. This task has been completed.

Task 3: (Milestone 10) Submission of a Journal Article Describing

the Infrared Equipment and Technique.

Compliance/Failure. This task is not complete.

Schedule Update. This task will be completed by May 31, 1992.

Task 4: Application for Financial Support from Gas Processors Association

Compliance/Failure. This task has been completed. The announcement of the awards is expected by September 31, 1991.

\section{Task 5: (Milestone 11) Development of Plan for Accelerating}

\section{Commercial Implementation}

Compliance/Failure. This task is partially completed. The original proposal stated that several areas would be developed to solicit future assistance from industrial sources. The first area was to increase the awareness of industry about this work and determine individual interests in amine mixture technology. Several presentations have been given to gas processing engineers working for industrial companies such as Texaco, Mobil, Oxy, Clayjon, Arco, Amoco, and Phillips. The second area for development was to find some corporate sources that are willing to supply VLE data at high acid gas concentrations. This VLE data will be used in the development and authentication tasks for amine mixtures during Phase II and III. Verbal interest has been easily obtained from several 
companies. This interest will be developed into active participation once the technique is proven in January 1992. The third area is to find some corporate sources that are willing to test the results of this work in pilot plant facilities. This commitment will result in the accelerated commercial implementation of this work by the participating corporations. This area will be developed during Phasi II and III.

Task 6: (Milestone 9) Revision of Project Economics

Compliance/Failure. This task is complete and included as a part of this report. 


\section{PROJECT ECONOMIC UPDATE}

The economic impact presented in the original proposal was based on energy estimates by Don Ballard ${ }^{[1]}$ and our own estimate of the gas purification capacity in the U.S. The original estimate was $3 \times 10^{14}$ BTU's saved in the year 2010. Several updates have been made in an attempt to more strongly substantiate this energy savings estimate. Two major industries, natural gas processing and petroleum refining, were targeted for substantiating the capacity estimate. The Oil and Gas Journal[6] reports the 1989 capacity for U.S. gas processors is $66 \times 10^{9} \mathrm{SCFD}$. We have obtained a refinery operations estimate by taking published refinery capacity figures and operating figures from the Amoco Refining Co. in Texas City, TX. ${ }^{[2,3]}$ We have estimated the total amount of gas processed in refineries at $29.3 \times 10^{9} \mathrm{SCFD}$. The calculations are outlined in letter dated July 15, 1991 and sent to Mr. Norm Swift. The amount of gas processed by these industries is about 95.3 billion standard cubic feet per day (BSCFD). MDEA based amines have the potential of saving energy in more than 28 BSCFD of this total processed volume. Our original estimate was based on the conversion of only 25 BSCFD of this volume. Our best estimates of the energy impact this project will have on the U.S. energy consumption is between 1 and $3.5 \times 10^{14}$ BTU's saved in the year 2010 . 


\section{References}

1 Ballard, Don; Energy Progress, 1986, vol. 6, no. 2, p. 112.

2 Corbett, Richard A.; "Capacity Rise Reflects Return to Better Times for U.S. Refiners", Oil \& Gas Journal, vol. 87, mar. 20,1989, p. 49+

3 Lucas, Kathleen; Amoco Refining, Texas City, TX, personal communication, Jul. 1991

4 Miessner, R. E. III, Energy Progress, :984, vol. 4, no. 1, p.17.

5 Schendel, R. L., Oil \& Gas J, 1982, vol 80, no. 43, p. 158.

6 True, Warren R.; "Worldwide Gas-processing Growth Slows", Oil \& Gas Journal, Jul. 9, 1990

$7 \quad$ United Gas Pipe Line Co., Oil \& Gas J, 1984, vol 82, no. 2, p 87. 
Figure 1

\section{ALKANOLAMINE \\ PURIFICATION \\ PROCESS}

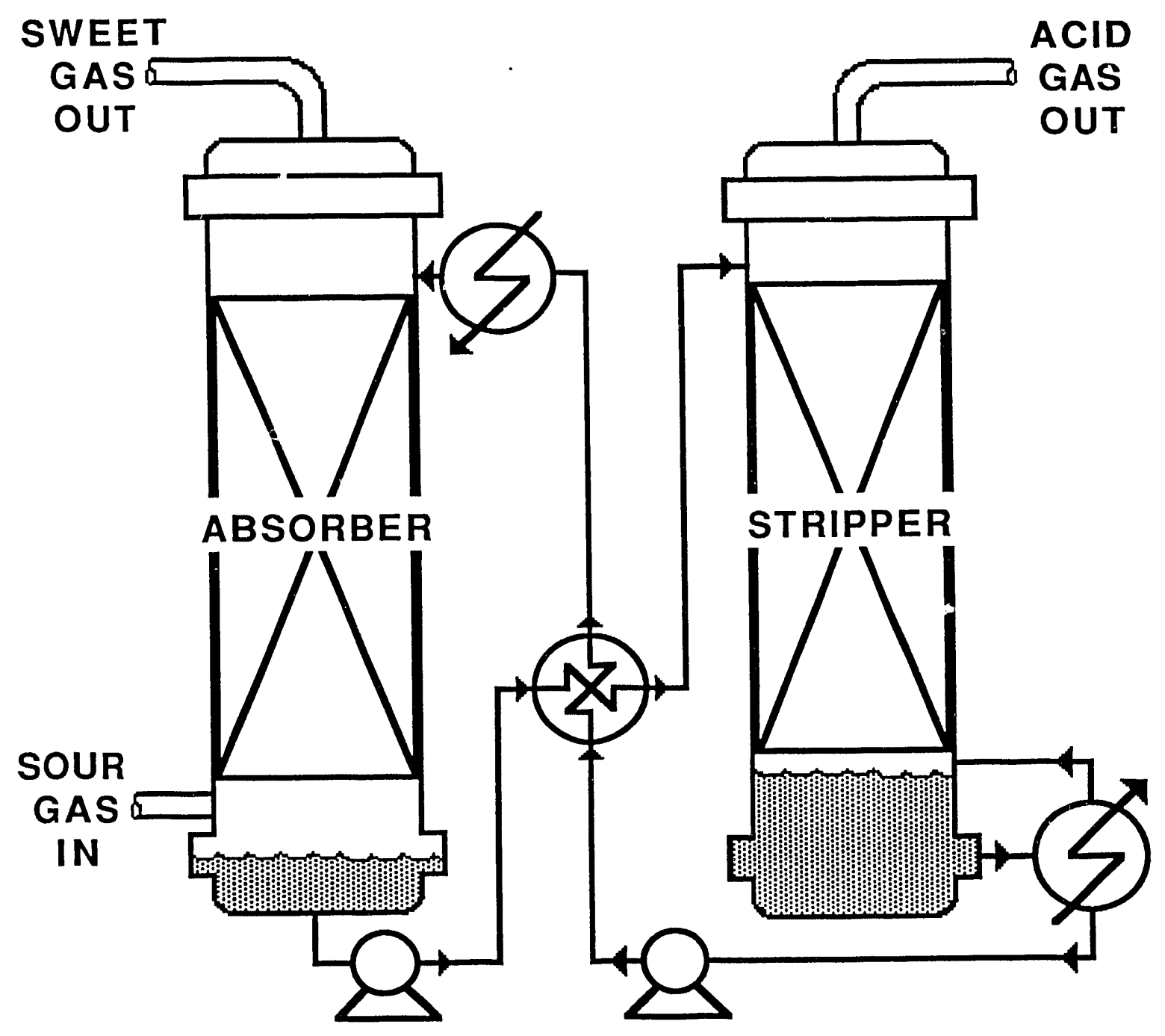




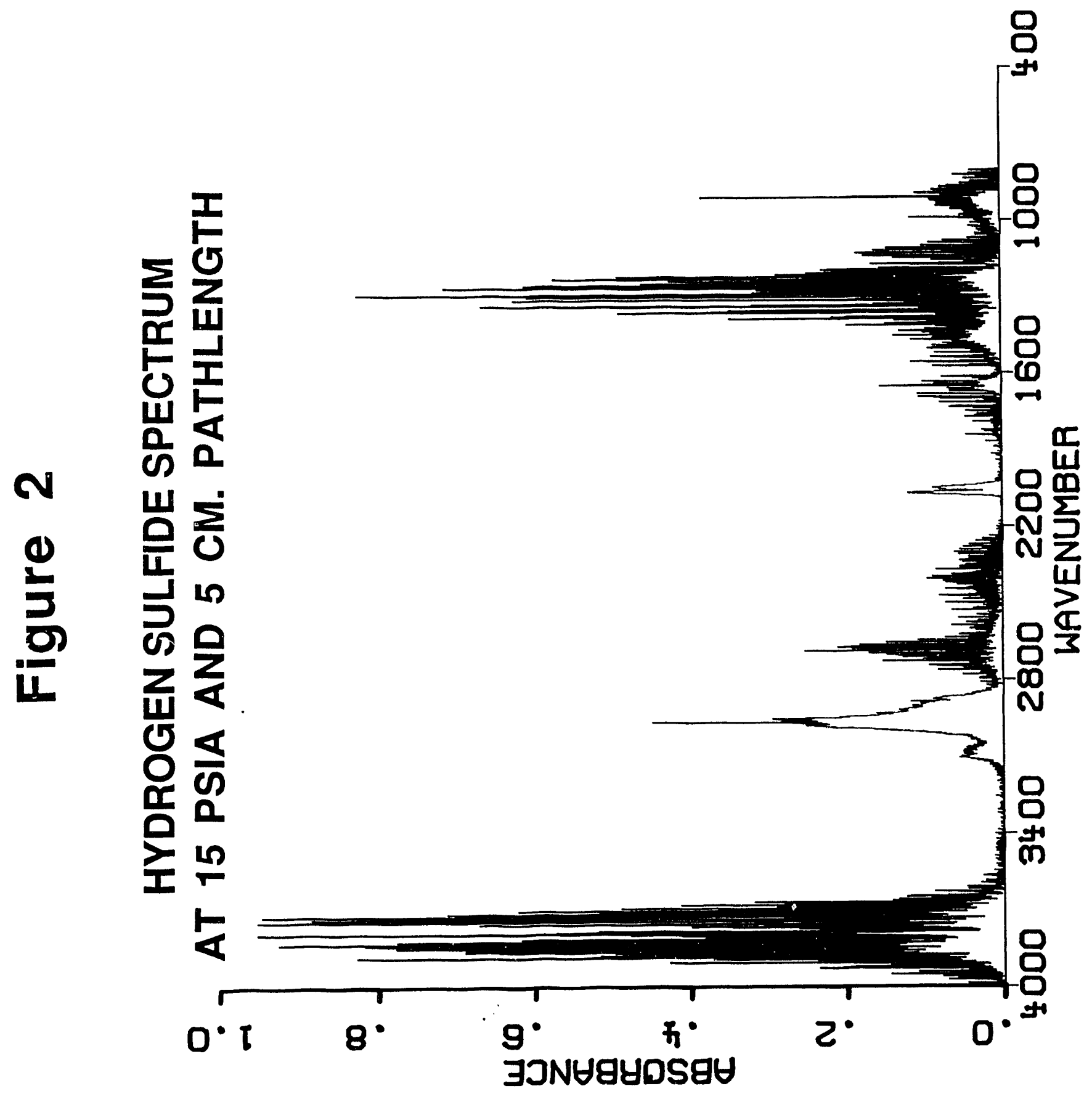




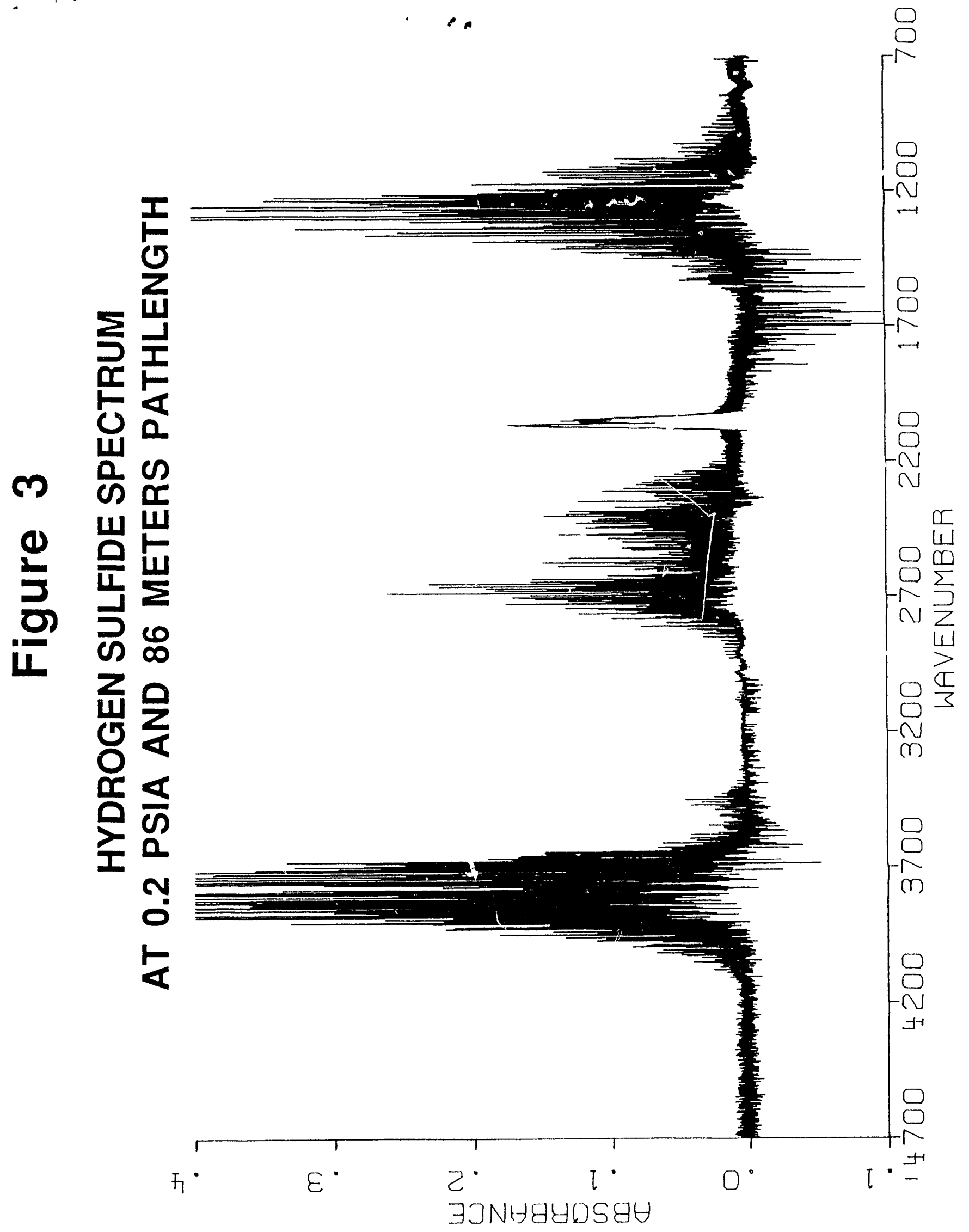



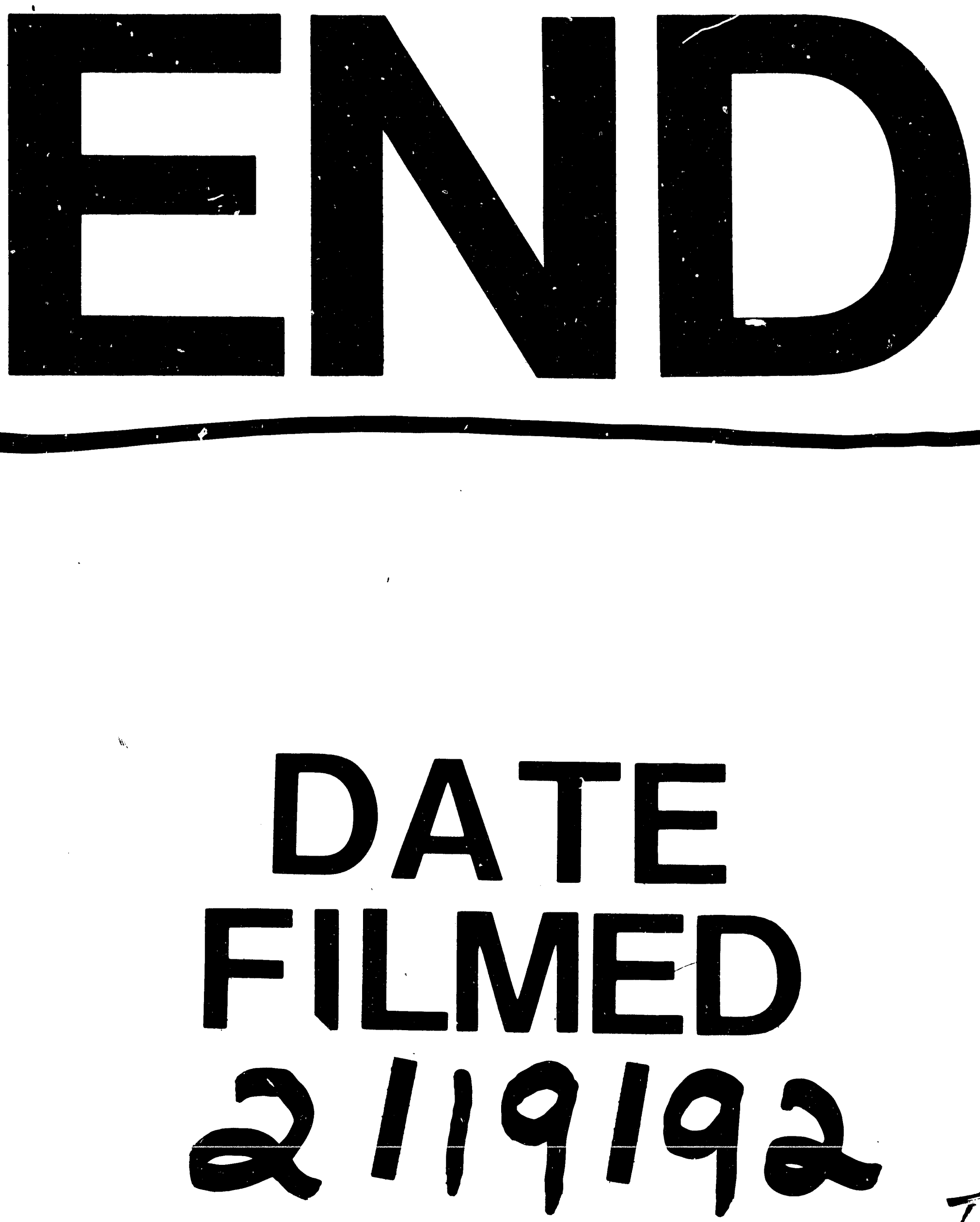

$I$ 
